\title{
Analysis of Dietary Intake and Body Composition of Female Athletes over a Competitive Season
}

\author{
Svetlana Nepocatych ${ }^{1}$, Gytis Balilionis ${ }^{1}$ and Eric K. O’Neal ${ }^{2}$
}

Affiliations: 'Elon University, Department of Exercise Science, Elon, USA, ${ }^{2}$ The University of North Alabama, Department of Health, Physical Education and Recreation, Florence, USA

Correspondence: Svetlana Nepocatych, Department of Exercise Science, Elon University, 100 Campus Dr., 2525 CB, Elon, NC 27244. E-mail: snepocatych@elon.edu

ABSTRACT The purpose of the study was to examine dietary intake, body composition and bone mineral density changes at the beginning and end of a competitive season in female athletes of sports that have been less represented in the literature. NCAA Division I basketball $(n=10)$ and softball $(n=10)$ players mean age

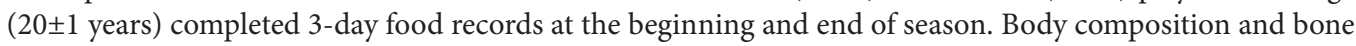
mineral density were measured using dual-energy X-ray absorptiometry (DXA). Mean energy intake was significantly lower at the beginning compared to the end of the season (1925 \pm 466 vs. $2326 \pm 782 \mathrm{kcals} /$ day; $\mathrm{p}=0.02$ ). Lean, fat, and total body mass, and total and regional BMD were unaltered from the beginning to the end of season $(\mathrm{p}>0.05)$. Macronutrient consumption by percentage did not change across the season ( $p>0.05$ ) with aggregate data equalling $3.5 \pm 1.3,1.2 \pm 0.6$, and $1.2 \pm 0.5 \mathrm{~g} / \mathrm{kg} / \mathrm{day}$ for carbohydrate, fat, and protein respectively. Carbohydrate and protein intakes were below the recommended levels. Low intake of fibre $(17 \pm 6.3 \mathrm{~g} /$ day $)$ and high sodium $(3700 \pm 1120 \mathrm{mg} /$ day $)$ also raise concerns. Despite no major alterations in body composition or BMD many female athletes' diets in the sports investigated while living on campus failed to meet recommended intake levels suggesting maximal athletic performance and health parameters may be stunted due to poor nutrient choices.

KEY WORDS Nutrients, Vitamins, Minerals, Performance, Dietary Behaviour, Bone Mineral Density.

@MJSSMontenegro

DIET AND BODY COMPOSITION OF FEMALE ATHLETES

http://mjssm.me/?sekcija=article\&artid=143

\section{Introduction}

Optimal health and athletic performance over a long and intense season is significantly influenced by training and dietary intake. Restrictive diet, increased demands for energy and certain nutrients may contribute to the increased risk of suboptimal dietary intake in athletes (Sammarone Turocy et al., 2011). Athletes participating in team and individual sports especially in basketball and softball have special nutritional considerations due to the extreme cardiovascular, metabolic and energy demands required for both practice and competition. Estimated energy expenditure (EER) for female athletes based on physical activity levels should range between $37-41 \mathrm{kcalkg}^{-1}$ per day (Trumbo, Schlicker, Yates, \& Poos, 2002). While athletes have energy reserves within the body, it is not sufficient to provide a continuous energy supply for longer periods of time and thus, need to be replenished. Adequate nutrition not only enhances an athlete's training, performance, and recovery, but also helps maintain appropriate body composition, immune, endocrine and musculoskeletal function (Burke, Loucks, \& Broad, 2006; Volpe, 2007). Changes in body composition and body weight due to inadequate energy intake or overconsumption may have a negative effect on an athlete's ability to perform and sustain activity during a competitive season (Rodriguez, DiMarco, \& Langley, 2009). In addition, maintaining a state of energy balance through adequate energy intake is required for an athlete to achieve appropriate intake of crucial macro- and micro- nutrients (Rodriguez et al., 2009). 
Athletes participating in moderate to high-level intensity training and competition should focus on consuming 6-10 g/kg/day of carbohydrate $(\mathrm{CHO})$ in order to maintain adequate blood glucose levels and replenish muscle glycogen stores (Campbell et al., 2007), 1.2-1.7 g/ kg/day of protein (PRO) to support nitrogen balance, spare amino acids for protein synthesis and to maintain optimum performance (Campbell et al., 2007). Previous research suggests that female athletes often fall short of meeting energy, carbohydrate and protein requirements based on activity levels (Clark, Reed, Crouse, \& Armstrong, 2003; Papadopoulou, Papadopoulou, \& Gallos, 2002). Furthermore, micronutrients play an essential role in energy metabolism, assist in tissues repair and recovery, transport of oxygen to the working muscles, maintenance of bone mineral density, and protection against oxidative stress. Thus, good nutrition practices are vital for maintaining good health, proper functioning of immune system, athletic performance, delaying fatigue, muscle growth and repair (Burke et al., 2006; Campbell et al., 2007).

College athletes have a unique training and living environment. Student athletes generally have very busy class, training and travel schedules that may impact their dietary practices habits, specifically the quantity and quality of the food consumed. Influences on athletes' dietary practices include the limited food choices on campus, access to grocery stores, late night studying, as well as the time or ability to prepare a home-cooked meal. Furthermore, food consumed on campus tends to be less healthy; higher in fat and added sugars compared to food cooked at home (Pelletier \& Laska, 2013). Previously, only one third of college students reported meeting Dietary Guidelines for Americans, 2000 for the five major food categories (Kolodinsky, Harvey-Berino, Berlin, Johnson, \& Reynolds, 2007). In addition, greater intake of fruits, dairy and protein was associated with greater food knowledge (Kolodinsky et al., 2007). Over the past few decades dietary intake and body composition changes occurred not only in the general but also in athletic populations, thus, there is a need to reassess nutrient intakes and dietary practices of college athletes (Hinton, Sanford, Davidson, Yakushko, \& Beck, 2004). Moreover, in recent decades, female sports have become more competitive, therefore, more athletes partake in dietary manipulation to elicit their desired body composition changes to improve peak performance.

Previous research has focused on the dietary practices and body composition of female athletes competing in soccer, volleyball, swimming, gymnastics, and distance running (Clark et al., 2003; Hassapidou \& Manstrantoni, 2001; Ousley-Pahnke, Black, \& Gretebeck, 2001; Papadopoulou et al., 2002). There is a paucity of data evaluating the dietary practices and, body composition of basketball and softball female athletes. We recognize that the training regimens and energy demands of these two sports do differ, however, the purpose of the present study was to examine the dietary intake of essential macro- and micro-nutrients from food sources over a 3-day period, and changes in body composition as well as the use of dietary supplements in NCAA Division I female athletes at the beginning compared to after the end of the competitive season.

\section{Methods}

Participants

Twenty-four NCAA Division I female athletes, between 18 and 22 years of age from basketball $(\mathrm{n}=13)$ and softball $(\mathrm{n}=11)$ teams were recruited for the study. A within subject repeated measures design (beginingto end of-season) was incorporated and comparisons were made between athletes of different sport when appropriate. Prior to the study all participants provided written informed consent form prepared in accordance and approved by the local Institutional Review Board for the protection of Human Participants. Data for dietary intake and body composition were collected twice during the competitive season at the beginning (before official games started) and at the end (immediately after the last tournament game was played). During this time, the athletes participated in regular in-season training including aerobic conditioning, skills, drills and weight training and competed on most weekends.

\section{Dietary Intake and Physical Activity Assessment}

Participants were asked to complete 3-day food records including two weekdays (Monday-Friday) and one weekend day (Saturday-Sunday). On the food records, participants recorded type, time, place, amount and method of preparation of food eaten. Participants were given written and verbal instructions by the investigator on how to record food intake including liquids, bites and sips, and were asked to be very specific regarding serving sizes and portions. In addition, participants were provided with a handout of portion sizes (e.g., 3 ounces of meat is the size of deck of playing cards) and sample dietary record forms to use throughout the day to help provide the most accurate food recall. The form included a sample breakfast, lunch, and dinner meals. If food was consumed at a restaurant, participants were asked to provide the name of the restaurant and specific food items ordered to allow for the most accurate nutrient analysis. All records were collected on the following day and were entered by the same two investigators to ensure consistency and accuracy.

Food records were entered and analysed for the total energy, macro- and micro- nutrient intake, food groups and energy expenditure using Nutritionist Pro ${ }^{\mathrm{Tm}}$ dietary analysis software (StandAlone Version, Axxya Systems, Stafford, TX). Macronutrient intake was compared to the recommendations found in the joint position stand "Nutrition and Athletic Performance" (Rodriguez et al., 2009). Micronutrient intake was compared to the Dietary Reference Intake (DRIs) (Institute of Medicine (IOM) Food and Nutrition Board, 2006). Also, participants were asked about their current multivitamin, single vitamin and mineral use over the past 30 days, reasons for dietary supplement use, sources of information regarding supplements, and who recommended dietary supplement use. 


\section{Anthropometric and Body Composition}

Participants were asked to provide demographic information including academic classification, ethnicity and sport team affiliation. Descriptive data including age, weight, and height were collected. Participants' body composition and bone mineral density were measured via dual energy X-ray absorptiometry (DXA; Lunar Prodigy Pro, GE HealthCare Lunar, Madison, WI). Total body mass (TBM), total lean body mass (LBM), fat mass (FM), percent body fat (BF \%), total bone mineral density (BMD), lumbar spine (L1-L4) and femur BMD were recorded. Participants bone mineral density scores were compared to a T-score. Osteopenia was characterized as having a T-score of -1.0 to -2.5 standard deviations below the mean of young adult reference values. The DXA instrument was calibrated every morning of the scheduled visits and assessment was completed by the same technician according to the manufacturer protocol.

\section{Statistical Analyses}

All data are presented as mean \pm SD. Maulchy's Test of Sphericity was used to test the assumption of sphericity. A time $\mathrm{x}$ group repeated measures analyses of variance ANOVA were used to compare differences between sports and time for macro- and micro-nutrient intake, body composition and BMD variables. Intakes of major vitamins and minerals were compared to DRIs and presented as $>25 \%$ or $10-25 \%$ below the recommended amount. Servings of the five major food groups were compared to the recommended serving sizes (U.S. Department of Health and Human Services (USDHHS) and U.S Department of Agriculture (USDA), 2015). An alpha value was set at 0.05 . Data analyses were carried out on Statistical Package for the Social Sciences version 21 (SPSS, Inc, IBM, Chicago, IL). All significance was accepted at $\mathrm{p} \leq 0.05$.

\section{Results}

Demographics

Basketball $(\mathrm{n}=10)$ and softball $(\mathrm{n}=10)$ players completed the study. The majority of the participants were Caucasian (70\%), followed by African American (25\%), Hispanic and other (5\%). On average participants were $20 \pm 1$ years of age with an average height of $172 \pm 10 \mathrm{~cm}$. There was no significant difference observed in TBM, LBM, BF\%, total BMD, L1-L4 BMD, or femur BMD ( $p>0.05)$ at the beginning compared to the end of the season (Table 1). However, LBM and total BMD was significantly $(\mathrm{p}<0.05)$ higher in basketball compared to softball players (Table 1). The total body, L1-L4, and femur BMD T-scores fell within the normal ranges for all the athletes.

TABLE 1 Body composition and bone mineral density over a competitive season for basketball and softball players (Mean \pm SD).

\begin{tabular}{|c|c|c|c|c|c|c|c|c|c|}
\hline & \multicolumn{2}{|c|}{ Basketball $(n=10)$} & \multicolumn{2}{|c|}{ Softball $(n=10)$} & \multicolumn{2}{|c|}{ Combined $(n=20)$} & \multirow{2}{*}{$\begin{array}{c}\mathrm{p} \text {-value } \\
\text { Time }\end{array}$} & \multirow[b]{2}{*}{$\begin{array}{l}\mathrm{p} \text {-value } \\
\text { Group }\end{array}$} & \multirow[b]{2}{*}{$\begin{array}{l}\mathrm{p} \text {-value } \\
\text { Time x } \\
\text { Group }\end{array}$} \\
\hline & Begining & End & Begining & End & Begining & End & & & \\
\hline Total Body Mass (kg) & $78.7 \pm 16.8$ & $80.1 \pm 18.6$ & $75.1 \pm 9.1$ & $73.2 \pm 8.6$ & $76.9 \pm 13.3$ & $76.6 \pm 14.5$ & 0.81 & 0.4 & 0.1 \\
\hline Body Fat (\%) & $28.2 \pm 7.6$ & $30.1 \pm 7.1^{\ddagger}$ & $34.1 \pm 7.3$ & $32.3 \pm 6.8^{\ddagger}$ & $31.2 \pm 7.9$ & $31.2 \pm 6.9$ & 0.95 & 0.21 & 0.04 \\
\hline Lean Body Mass (kg) & $48.3 \pm 5.1^{*}$ & $48.1 \pm 6.2^{*}$ & $42.9 \pm 2.6$ & $43.1 \pm 3.0$ & $45.6 \pm 4.8$ & $45.6 \pm 5.4$ & 0.96 & 0.02 & 0.65 \\
\hline Total BMD $\left(\mathrm{g} / \mathrm{cm}^{3}\right)$ & $1.35 \pm 0.06^{*}$ & $1.35 \pm 0.06^{*}$ & $1.29 \pm 0.03$ & $1.29 \pm 0.04$ & $1.32 \pm 0.06$ & $1.32 \pm 0.06$ & 0.67 & 0.02 & 0.82 \\
\hline Femur BMD $\left(\mathrm{g} / \mathrm{cm}^{3}\right)$ & $1.27 \pm 0.09$ & $1.31 \pm 0.12$ & $1.21 \pm 0.12$ & $1.23 \pm 0.12$ & $1.24 \pm 0.11$ & $1.27 \pm 0.13$ & 0.17 & 0.12 & 0.61 \\
\hline L1-L4 Trend BMD ( $\left.\mathrm{g} / \mathrm{cm}^{3}\right)$ & $1.47 \pm 0.14$ & $1.47 \pm 0.16$ & $1.45 \pm 0.1$ & $1.42 \pm 0.11$ & $1.46 \pm 0.12$ & $1.45 \pm 0.05$ & 0.35 & 0.53 & 0.12 \\
\hline
\end{tabular}

*Significant difference between the beginning and end of competitive season, $p \leq 0.05$.

\#Significant difference between two groups over time, $p \leq 0.05$.

\section{Total Energy and Macronutrient Intake}

The average of 3-day total energy and macronutrient intake are presented in Table 2 . There was a significantly lower energy intake observed at the beginning compared to the end of the season in both teams (1925 $\pm 466 \mathrm{vs}$. $2326 \pm 782 \mathrm{kcals}, \mathrm{p}<0.05)$. In addition, a lower energy intake was reported by softball compared to basketball players $(\mathrm{p}<0.05)$. Lower $\mathrm{CHO}(3.1 \pm 0.9$ vs. $3.9 \pm 1.4 \mathrm{~g} / \mathrm{kg} / \mathrm{day}, \mathrm{p}<0.05)$ and fat $(1.0 \pm 0.4 \mathrm{vs.} 1.4 \pm 0.7 \mathrm{~g} / \mathrm{kg} / \mathrm{day}$, $\mathrm{p}<0.05)$ intake was observed at the beginning compared to the end of the season, respectively. In addition, fat intake but not carbohydrate intake was higher $(\mathrm{p}<0.05)$ in basketball compared to softball players. Fat intake was at the higher end with $55 \%$ of female athletes exceeding general recommendations of $20-35 \%$ (Hedrick Fink \& Mikesky, 2015; Trumbo et al., 2002). No significant difference ( $p>0.05)$ was observed for protein and fibre intake at the beginning compared to the end of the season or between the sports (Table 2). However, $45 \%$ of the athletes consumed below the recommended 1.2-1.7 g// kg/day of protein for athletes of similar sports both at the beginning and at the end of the season. On average, athletes consumed $68 \%$ and $72 \%$ of $25 \mathrm{~g}$ of fibre that is recommended per day at the beginning and end of the season, respectively (Trumbo et al., 2002). In addition, fibre intake significantly increased in basketball and significantly decreased in softball players $(\mathrm{p}<0.05)$ at the beginning compared to the end of the season and yet it did not reach the recommended level. Cholesterol intake was not significantly different at the beginning compared to the end of the season, 
TABLE 2 Total calorie and macronutrient intake over a competitive season for basketball and softball players (Mean \pm SD). Recommendations for total calories, carbohydrate, protein and fat intake per day based on average weight of study participants.

\begin{tabular}{|c|c|c|c|c|c|c|c|c|c|c|}
\hline & \multirow[b]{2}{*}{ Recommended } & \multicolumn{2}{|c|}{ Basketball $(n=10)$} & \multicolumn{2}{|c|}{ Softball $(n=10)$} & \multicolumn{2}{|c|}{ Combined $(n=20)$} & \multirow[b]{2}{*}{$\begin{array}{l}\mathrm{p} \text {-value } \\
\text { Time }\end{array}$} & \multirow[b]{2}{*}{$\begin{array}{l}\mathrm{p} \text {-value } \\
\text { Group }\end{array}$} & \multirow[b]{2}{*}{$\begin{array}{l}\text { p-value } \\
\text { Time } x \\
\text { Group }\end{array}$} \\
\hline & & Begining & End & Begining & End & Begining & End & & & \\
\hline \multicolumn{11}{|l|}{ Energy Intake } \\
\hline Per day (kcal) & 2719-3019 & $2208 \pm 373$ & $2567 \pm 834^{*+}$ & $1641 \pm 375$ & $2085 \pm 682^{*+}$ & $1925 \pm 466$ & $2326 \pm 782$ & 0.02 & 0.03 & 0.8 \\
\hline Per body weight (kcal/kg) & $37-41$ & $29 \pm 8$ & $34 \pm 15^{*}$ & $23 \pm 6$ & $29 \pm 12^{*}$ & $32 \pm 13$ & $26 \pm 8$ & 0.02 & 0.21 & 0.77 \\
\hline \multicolumn{11}{|l|}{ Carbohydrate } \\
\hline Per day (gm) & $441-735$ & $254 \pm 51$ & $304 \pm 74^{*}$ & $207 \pm 44$ & $259 \pm 79 *$ & $230 \pm 52$ & $281 \pm 78$ & 0.001 & 0.1 & 0.94 \\
\hline Per body weight (g/kg) & 6-10 & $3.4 \pm 1.0$ & $4.1 \pm 1.5^{*}$ & $2.9 \pm 0.7$ & $3.7 \pm 1.3^{*}$ & $3.1 \pm 0.9$ & $3.9 \pm 1.4$ & 0.001 & 0.28 & 0.61 \\
\hline Energy Ratio (\%) & $45-65$ & $46 \pm 6$ & $50 \pm 14$ & $51 \pm 8$ & $50 \pm 6$ & $49 \pm 7$ & $50 \pm 10$ & 0.63 & 0.28 & 0.46 \\
\hline \multicolumn{11}{|l|}{ Protein } \\
\hline Per day (gm) & $88-132$ & $92 \pm 29$ & $97 \pm 38$ & $73 \pm 11$ & $86 \pm 30$ & $89 \pm 23$ & $92 \pm 34$ & 0.31 & 0.13 & 0.64 \\
\hline Per body weight (g/kg) & $1.2-1.8$ & $1.3 \pm 0.6$ & $1.4 \pm 0.7$ & $1 \pm 0.2$ & $1.2 \pm 0.5$ & $1.1 \pm 0.4$ & $1.3 \pm 0.6$ & 0.3 & 0.27 & 0.56 \\
\hline Energy Ratio (\%) & $10-35$ & $17 \pm 5$ & $15 \pm 2$ & $18 \pm 3$ & $17 \pm 3$ & $18 \pm 4$ & $16 \pm 3$ & 0.13 & 0.21 & 0.9 \\
\hline \multicolumn{11}{|l|}{ Fat } \\
\hline Per day (gm) & $60-117$ & $87 \pm 19$ & $111 \pm 42^{*+}$ & $56 \pm 17$ & $89 \pm 39^{* \dagger}$ & $71 \pm 24$ & $96 \pm 39$ & 0.01 & 0.006 & 0.94 \\
\hline Per body weight (g/kg) & $0.8-0.9$ & $1.2 \pm 0.3$ & $1.6 \pm 0.9^{* \dagger}$ & $0.8 \pm 0.3$ & $1.3 \pm 0.6^{* \dagger}$ & $1.0 \pm 0.4$ & $1.4 \pm 0.7$ & 0.02 & 0.05 & 0.98 \\
\hline Energy Ratio (\%) & $20-35$ & $35 \pm 5$ & $39 \pm 7^{*+}$ & $31 \pm 7$ & $38 \pm 12^{* \dagger}$ & $33 \pm 6$ & $37 \pm 6$ & 0.05 & 0.03 & 0.99 \\
\hline Fiber (gm) & 25 & $15 \pm 4$ & $20 \pm 8^{\ddagger}$ & $19 \pm 6$ & $16 \pm 7^{\ddagger}$ & $17 \pm 5$ & $18 \pm 7$ & 0.35 & 0.88 & 0.01 \\
\hline Cholesterol (mg) & $>300$ & $459 \pm 286$ & $399 \pm 178^{+}$ & $183 \pm 54$ & $243 \pm 108^{+}$ & $321 \pm 246$ & $321 \pm 164$ & 0.99 & 0.003 & 0.24 \\
\hline
\end{tabular}

Note. Kcal: kilocalories; kcal/kg: kilocalories per kilogram of body weight; gm: grams; g/kg: grams per kilogram of body weight; mg: milligrams.

*Significant difference between the beginning and end of competitive season, $\mathrm{p} \leq 0.05$.

†Significant difference between bsketball and softball players, $\mathrm{p} \leq 0.05$.

$\ddagger$ Significant difference between two groups over time, $\mathrm{p} \leq 0.05$.

however, was significantly $(\mathrm{p}<0.05)$ higher in basketball compared to softball players (Table 2). Furthermore, most athletes on average consumed less than recommended amounts of vegetables, fruits, dairy and protein foods (Figure 1).

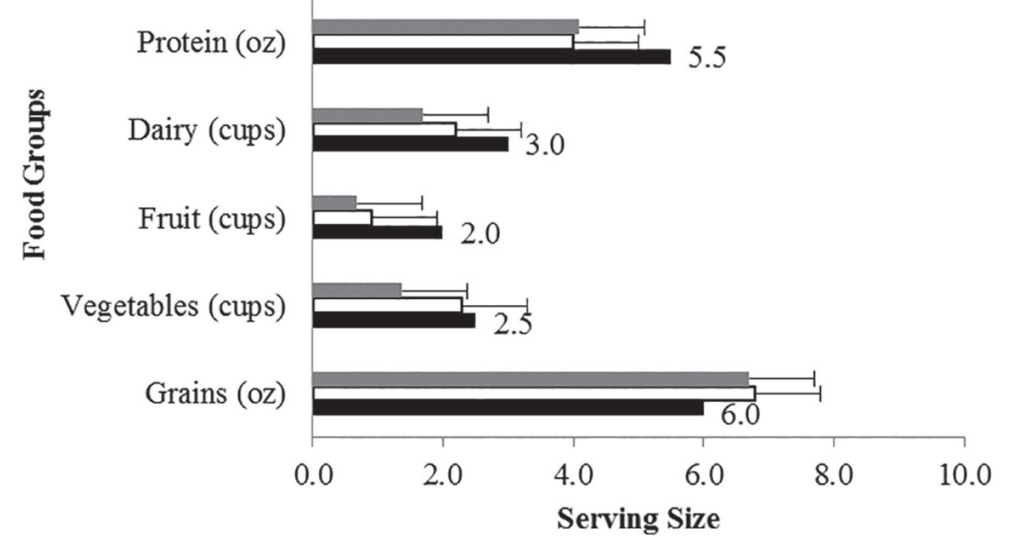

End of season

口Beginning of season

- Recommendations

FIGURE 1 Average consumption of five major food groups at the beginning and end of the season compared to the recommended servings sizes by USDA $(n=20)$

Note. oz: ounces

\section{Micronutrients}

There was no significant difference ( $\mathrm{p}>0.05)$ in vitamin and mineral intake from food sources at the beginning compared to the end of the season (Table 3). Lower intakes compared to DRIs were observed for average potassium, iron, magnesium, calcium, vitamin $\mathrm{E}$ at the beginning and end of the season. Vitamin A, vitamin E, magnesium and zinc were $>25 \%$ below and calcium, potassium, and iron were at least $10-25 \%$ below DRIs for females of similar age. A significantly higher $(\mathrm{p}<0.05)$ sodium and niacin intake above DRIs was observed. $55 \%$ of participants reported using multivitamins over a competitive season; however, inconsistent use of dietary supplements was reported. Six participants reported taking multivitamin on a regular basis. Occasional use was reported for iron, magnesium, folic acid, Vitamin C, Vitamin B6, Vitamin B12 and Vitamin D. Most common reasons for dietary supplement use were to improve and maintain health (25\%), prevent health problems (25\%), get more energy (20\%) and boost immune system (15\%). Major sources of information regarding dietary supplements were dietician (30\%), physician (25\%) or coaches $(20 \%)$. Most of the time participants initiated dietary supplement use themselves (20\%) or following an advice from coaches (20\%). 
TABLE 3 Comparison of vitamin and mineral intake to DRI over a competitive season for basketball and softball (Mean \pm SD).

Basketball $(n=10) \quad$ Softball $(n=10) \quad$ Combined $(n=20)$

\begin{tabular}{|c|c|c|c|c|c|c|c|c|c|c|}
\hline & $\begin{array}{c}\text { DRI } \\
(19-30 y)\end{array}$ & Beginning & End & Beginning & End & Beginning & End & $\begin{array}{l}\mathrm{p} \text {-value } \\
\text { Time }\end{array}$ & $\begin{array}{l}\mathrm{p} \text {-value } \\
\text { Group }\end{array}$ & $\begin{array}{l}\mathrm{p} \text {-value } \\
\text { Time x } \\
\text { Group }\end{array}$ \\
\hline Vitamin A $(\mu \mathrm{g})$ RAE & 700 & $369 \pm 357^{b}$ & $694 \pm 955$ & $382 \pm 219^{b}$ & $496 \pm 403^{b}$ & $376 \pm 288^{a}$ & $595 \pm 721^{b}$ & 0.19 & 0.64 & 0.52 \\
\hline Vitamin C (mg) & 75 & $110 \pm 88$ & $158 \pm 205$ & $100 \pm 93$ & $136 \pm 119$ & $105 \pm 70$ & $147 \pm 164$ & 0.27 & 0.72 & 0.87 \\
\hline Vitamin E (mg) & 15 & $4.1 \pm 5.8^{b}$ & $4.9 \pm 4.3^{b}$ & $4 \pm 3.6^{b}$ & $3.2 \pm 2.2^{b}$ & $4.1 \pm 4.6^{b}$ & $4.1 \pm 3.5^{b}$ & 0.98 & 0.5 & 0.54 \\
\hline Thiamin(mg) & 1.1 & $1.1 \pm 0.6$ & $1.3 \pm 0.6$ & $1.3 \pm 0.4$ & $1.2 \pm 0.4$ & $1.2 \pm 0.5$ & $1.2 \pm 0.5$ & 0.58 & 0.79 & 0.30 \\
\hline Riboflavin (mg) & 1.1 & $1.2 \pm 0.6$ & $1.5 \pm 0.9$ & $1.7 \pm 1.3$ & $1.6 \pm 0.7$ & $1.5 \pm 1.0$ & $1.6 \pm 0.8$ & 0.72 & 0.43 & 0.36 \\
\hline Niacin (mg) & 14 & $15.5 \pm 9$ & $21.7 \pm 13.9$ & $18.3 \pm 4.8$ & $22.9 \pm 11.2$ & $16.9 \pm 7.2$ & $22.3 \pm 12.3$ & 0.07 & 0.6 & 0.79 \\
\hline Vitamin B6 (mg) & 1.3 & $1.3 \pm 0.8$ & $1.6 \pm 1.2$ & $1.7 \pm 0.8$ & $1.8 \pm 0.7$ & $1.5 \pm 0.8$ & $1.7 \pm 1.0$ & 0.38 & 0.46 & 0.67 \\
\hline Folate $(\mu \mathrm{g})$ & 400 & $349 \pm 351^{\mathrm{a}}$ & $423 \pm 265$ & $542 \pm 340$ & $399 \pm 197$ & $445 \pm 351$ & $411 \pm 228$ & 0.65 & 0.45 & 0.17 \\
\hline Vitamin B12 $(\mu \mathrm{g})$ & 2.4 & $3 \pm 2.5$ & $5.1 \pm 5.3$ & $3.3 \pm 2.4$ & $3.7 \pm 1.7$ & $3.2 \pm 2.4$ & $4.4 \pm 3.9$ & 0.25 & 0.57 & 0.43 \\
\hline Calcium (mg) & 1000 & $817 \pm 330^{\mathrm{a}}$ & $720 \pm 282^{b}$ & $617 \pm 204^{b}$ & $683 \pm 285^{b}$ & $717 \pm 286^{b}$ & $702 \pm 277^{b}$ & 0.85 & 0.23 & 0.32 \\
\hline Selenium (mcg) & 55 & $65 \pm 40$ & $87 \pm 45$ & $79 \pm 22$ & $72 \pm 38$ & $72 \pm 32$ & $80 \pm 41$ & 0.54 & 0.98 & 0.23 \\
\hline Magnesium & 310 & $174 \pm 92^{b}$ & $200 \pm 100^{b}$ & $216 \pm 71^{b}$ & $210 \pm 107^{b}$ & $195 \pm 83^{b}$ & $205 \pm 101^{b}$ & 0.66 & 0.46 & 0.50 \\
\hline Iron (mg) & 18 & $15 \pm 6^{\mathrm{a}}$ & $14 \pm 7^{\mathrm{a}}$ & $13 \pm 5^{b}$ & $16 \pm 9^{a}$ & $14 \pm 6^{a}$ & $15 \pm 8^{\text {a }}$ & 0.70 & 0.91 & 0.18 \\
\hline Zinc (mg) & 8 & $6 \pm 4^{b}$ & $8 \pm 6$ & $8 \pm 3$ & $8 \pm 5$ & $7 \pm 3$ & $8 \pm 5$ & 0.30 & 0.48 & 0.62 \\
\hline Potassium (mg) & 4700 & $1544 \pm 563^{b}$ & $2298 \pm 1519^{b}$ & $1873 \pm 566^{b}$ & $1983 \pm 735^{b}$ & $1709 \pm 575^{b}$ & $2141 \pm 1172^{b}$ & 0.07 & 0.99 & 0.17 \\
\hline Sodium (mg) & 1500 & $4413 \pm 984$ & $4259 \pm 963^{+}$ & $2872 \pm 632$ & $3292 \pm 1131^{\dagger}$ & $3643 \pm 1128$ & $3776 \pm 1136$ & 0.65 & 0.001 & 0.34 \\
\hline
\end{tabular}

Note. DRI: Dietary Reference Intake; RAE: Retinol Activity Equivalent; mg: milligrams; $\mu \mathrm{g}$ : micrograms.

†Significant difference between bsketball and softball players, $p \leq 0.05$.

$\mathrm{a}=>10-25 \%$ below DRI, $\mathrm{b}=>25 \%$ below DRI.

\section{Discussion}

Several key findings emerged from this study, the 3-day food records indicated inadequate intake of many crucial macro- and micro-nutrients through diet which are critical for energy metabolism, glycogen replenishment, neutralization of free radicals and bone health in young female athletes. In addition, participants did not meet general recommendations for total energy intake, major macronutrients including carbohydrate, fibre and protein and over consumed fat.

\section{Energy}

In the present study, mean energy intake was reported below what would be recommended for females of similar age and activity levels. Based on Estimated Energy Requirements (EER) very active female athletes may need to consume anywhere between 2,637-3,211 kcals/day (Trumbo et al., 2002). Energy intake for these participants at the beginning of the season averaged $1925 \mathrm{kcals} /$ day falling within the range of low active individuals and at the end of the season $2326 \mathrm{kcals} /$ day failing to meet the energy needs for active women of the same age (Trumbo et al., 2002). In addition, energy intake did not improve over the competitive season and was lower compared to what would be expected for their energy expenditure. Nonetheless, the observations of the present investigation are in agreement with the results of previous studies that have used dietary recalls to analyse energy intake. Previous studies have consistently demonstrated that female athletes consume insufficient amount of calories and are in a negative energy balance. (Clark et al., 2003; Hassapidou \& Manstrantoni, 2001; Hinton et al., 2004; Mullinix, Jonnalagadda, Rosenbloom, Thompson, \& Kicklighter, 2003; Papadopoulou et al., 2002; Petersen et al., 2006). Female athletes participating in varsity sports consistently report an average energy intake that meets the minimum requirements for women of similar age who participate in light-to moderate physical activity (Clark et al., 2003; Hinton et al., 2004; Petersen et al., 2006). In addition, similarly lower energy intakes compared to energy expenditures were observed among other sports including volleyball, distance runners, ballet dancers and swimmers while in training and competitive seasons. (Hassapidou \& Manstrantoni, 2001; Papadopoulou et al., 2002). Consequently, chronic low energy intake may be detrimental to athlete's performance and overall health. It can lead to inadequate energy levels during exercise and body composition changes that can negatively affect athletic performance and recovery.

\section{Body composition}

In the present study, no significant body composition changes were observed due to reported lower energy intake. As presented in Table 1, a non-significant change in total body mass and $\mathrm{BF} \%$ was observed in athletes over time with no change in LBM. Previously, a decrease in BF\% and increase in LBM while in negative energy balance was observed among swimmers and divers at preseason compared to the late season (Petersen et al., 
2006), whereas, Clark et al. (2003) observed no significant changes in total body weight pre- and post-season in female soccer players. Therefore, the results of the present study support the findings of Clark et al. (2003). In addition, a large individual variability was observed between athletes with energy intake ranging between 1,247 to $2,961 \mathrm{kcals} /$ day at the beginning and 1,150 to $4,131 \mathrm{kcals} /$ day at the end of the season. Thus, some athletes may have been in a positive energy balance. Nonetheless, the lack of body composition changes due to lower energy intake could be explained by using estimated energy expenditure based on previous literature and not actually measured. Athletes may have underestimated food intake or increased consumption of food before or after the completion of the three day food records compensating for energy imbalance. (Petersen et al., 2006). Also, athletes may have been more conscious and aware of foods eaten altering the type and amount of food consumed affecting their reported food and energy intake.

A higher total body weight, LBM, BMD and lower BF\% was observed in basketball players compared to softball athletes. The difference in weight and body fat $\%$ among softball and basketball players could be related to the difference in the type and exercise intensity performed during training and competition. Average BF\% fell at the higher end of healthy BF\% ranges, however, varied greatly between the athletes (Gallagher et al., 2000). Previously, lower BF\% were consistently reported for female athletes of similar sports including soccer ( 16\%), softball (21\%), basketball (16\%), and volleyball players (19-23\%) (Clark et al., 2003; Hassapidou \& Manstrantoni, 2001; Malousaris et al., 2008; Petersen et al., 2006; Tsunawake et al., 2003). However, most of investigations observed elite female athletes whose level, type and amount of training may have been different compared to Division I college athletes. In addition, significant changes in size, body composition and dietary behaviours have been observed in the past few decades among general and athletic populations (Wilborn et al., 2005). Athletes may have higher total body weight and body fat making it difficult to compare past and present studies (Wilborn et al., 2005). Moreover, different methods for measuring body composition were previously used by the studies including skinfolds (Hassapidou \& Manstrantoni, 2001; Malousaris et al., 2008; Tsunawake et al., 2003) and hydrostatic weighing (Clark et al., 2003; Tsunawake et al., 2003). As a result, a three component model of body composition employed by DXA may have been more accurate in assessing BMD, LBM and FM compared to two-component model employed by skinfolds and hydrostatic weighing causing discrepancies (Kohrt, 1998).

Desire to lose weight and reduce BF\% could lead to severe dietary restrictions and lower energy intakes (Sammarone Turocy et al., 2011). Athletes may feel pressure to achieve or maintain lower body weight therefore may self-select to restrict calorie and carbohydrate intake by following low carbohydrate and highprotein diets or skipping meals (Mullinix et al., 2003). Therefore, this may indicate that athletes may lack proper education and knowledge of how such dietary restrictions during a competitive season may negatively affect their performance. Thus, could benefit from nutrition education by a registered dietician.

Additionally, in order to maintain optimal agility, speed, power, and strength especially in sports where multidirectional movements are performed achieving greater lean muscle mass to fat ratio would be advantageous (Kovacs, 2007; Rodriguez et al., 2009). Although, reported lower energy intakes would lead to body composition changes and optimal physique for some of the athletes it should not be implemented during a competitive season. Extreme weight gains and losses during a competitive season may lead to negative consequences including loss in skeletal muscle mass, hormone imbalances and impaired athletic performance, thus, should be achieved during pre- or off-season training by carefully manipulating diet and training to minimize the impact (Burke et al., 2006; Wilborn et al., 2005).

\section{Macronutrient Intake}

In the present study, most of the participants were at the lower end of general recommendations of consuming 45 - 65\% of total daily calories as carbohydrates (Hedrick Fink \& Mikesky, 2015; Rodriguez et al., 2009; Trumbo et al., 2002). In addition, athletes should be consuming on average $6-10 \mathrm{~g} / \mathrm{kg} / \mathrm{day}$ of carbohydrates depending on daily energy expenditure. In the present study, only $10 \%$ of athletes consumed the recommended amount of $\mathrm{CHO}$, whereas, most of the participants consumed less than $50 \%$ of the lower end of recommended intake. Previously, similar results were observed among basketball, soccer, cross-country runners, and track and field athletes (Mullinix et al., 2003; Shriver, Betts, \& Wollenberg, 2013). Clark et al. (2003) observed carbohydrate intake of $5.2 \pm 1.1 \mathrm{~g} / \mathrm{kg} /$ day and $4.3 \pm 1.2 \mathrm{~g} / \mathrm{kg} /$ day with $\mathrm{CHO}$ composition of $55 \%$ and $57 \%$ of total calories during pre- and post-season, respectively. Similarly, Hassapidou and Mastrantoni (2001) observed low $\mathrm{CHO}$ intake in adolescent volleyball players of $3.1 \pm 1.4 \mathrm{~g} / \mathrm{kg} /$ day with $\mathrm{CHO}$ composition of $46 \%$. It has been observed that athletes consuming higher energy intakes (i.e. 4000-5000 kcals/day) often will meet or exceed their $\mathrm{CHO}$ requirements based on \% of total energy compared to athletes with lower energy intakes (Burke, Cox, Cummings, \& Desbrow, 2001). Diets with low total energy intake where 60-65\% of energy is supplied by carbohydrates may still be insufficient to replenish muscle and liver glycogen stores depleted during training or competition (Martin, Lambeth, \& Scott, 2006). Hence, it has been suggested that athletes should be provided with gender and sport specific $\mathrm{CHO}$ recommendations in grams relative to body weight to allow for flexibility consuming $\mathrm{CHO}$ based on their daily energy needs and nutritional goals (Burke et al., 2001).

While evaluating dietary intake based of the self-report we should not only consider the extent of underreporting and under-estimating food intake but also other dietary habits (Black et al., 1991; Burke et al., 
2001). Lower CHO intake could be attributed to increased consumption of dietary fat and high-protein foods substituting intake of $\mathrm{CHO}$ and other important nutrients. Previously, similar findings were observed by multiple investigations among female athletes (Hassapidou \& Manstrantoni, 2001; Mullinix et al., 2003; Papadopoulou et al., 2002). In addition, fat intake was at the higher end of recommended percent of total calories with 55\% of the participants exceeding the higher end of recommended intake. Although, higher fat intake may be beneficial resulting in glycogen sparing and increased fat oxidation due substrate availability in a short term, over a longer period muscle and liver glycogen stores will be reduced negatively affecting ability to perform and train at the intended level (Jeukendrup, 2003). There was no significant difference in energy derived from protein over a competitive season. On average participants consumed enough protein based on general recommendation of $0.8 \mathrm{~g} / \mathrm{kg} / \mathrm{day}$ and stayed within the range for energy ratio derived from protein (Hedrick Fink \& Mikesky, 2015). However, some experts suggest that physically active individuals engaging in endurance exercise should consume 1.2-1.4 g/ $\mathrm{kg} /$ day and those who engage in weight training up to 1.8 $\mathrm{g} / \mathrm{kg} /$ day (Hedrick Fink \& Mikesky, 2015; Rodriguez et al., 2009). In the present study, only 55\% of athletes consumed at least $1.2 \mathrm{~g} / \mathrm{kg} /$ day of protein and fell below the recommended levels for active individuals. Similar results were observed in female soccer players (Clark et al., 2003), volleyball players (Hassapidou \& Manstrantoni, 2001; Papadopoulou et al., 2002) and other college varsity sports (Hinton et al., 2004). Due to observed poor nutritional habits athletes may greatly benefit from altering proportional intake of macro-nutrients. Increased $\mathrm{CHO}$ consumption would be advised especially complex $\mathrm{CHO}$ which would help increase not only fibre intake but also other important micro-nutrients of concern while substituting foods with higher fat content and empty calories.

\section{Micronutrients and Food Groups}

College students and athletes consume most of their meals away from home and often on college campus. Usually these meals are characterized as being higher in energy, total fat, cholesterol, sodium, added sugars and lack in nutrient content (Guthrie, Lin, \& Frazao, 2002; Kolodinsky et al., 2007; Pelletier \& Laska, 2013). Higher fat, cholesterol, sodium and lower fibre intakes were observed in the present study. In addition, athletes failed to meet the recommendations for five major food group categories, which is typical of modern diet. Athletes consumed less grains, vegetables, fruits and dairy. In addition, insufficient energy intakes as well as low fruit, veggie and dairy intakes corresponds well with lower nutrient content and lack of crucial vitamins, minerals and fibre. Athletes did not meet the DRIs of many crucial nutrients. Similar results were previously found by Hassapidou and Mastrantoni (2001) and Clark et al. (2003). Although, some athletes reported taking supplements, the use was inconsistent. The lack of these nutrients over time could lead to nutrient deficiencies that are detrimental to athletic performance and overall health; therefore, nutritional counselling specific to these micronutrients should be advised (Rodriguez et al., 2009). Nutrition knowledge tends to be related to the individual's food choices and positively relates to healthier eating patterns (Kolodinsky et al., 2007). This may suggest that female athletes may not be knowledgeable enough to make healthy food-related decisions and understand the implications of nutrition on health and sports performance. Nutrition intervention by a registered dietician has been shown to improve nutrition knowledge, body composition, total energy, $\mathrm{CHO}$, PRO and micronutrient intake among athletes (Anderson, 2010; Valliant, Pittman Emplaincourt, Kieckhaefer Wenzel, \& Garner, 2012; Wenzel Kieckhaefer, Valliant Wells, Chang, Bomba K., \& Lambert G., 2012). In addition, nutrition labels at the dining halls can be used as a tool for educating athletes how to improve their food choices to meet daily energy needs and nutrient requirements (Driskell, Schake, \& Detter, 2008).

\section{Limitations}

Some challenges when interpreting self-reported dietary intake data should be considered. Previously, failure to report all foods consumed and higher underestimation of habitual food intake was observed among women compared to men (Black et al., 1991; Burke et al., 2001). Although, participants were educated on how to record the food and fluid intake to minimize the impact they were not used to doing it on a regular basis. In addition, the types of foods they consumed may have been influenced by individual athlete's class schedules and food availability at the dining halls. Although, athletes were asked to indicate unusual intake it is difficult to determine wherever this 3-day period represented their habitual dietary intake.

In conclusion, dietary recalls indicated inadequate intake of many crucial macro- and micro-nutrients through diet of student athletes living on campus which are critical for energy metabolism, glycogen replenishment, neutralization of free radicals and bone health in young female athletes. The lack of these nutrients could potentially be affecting athletic performance and overall health; therefore, nutritional counselling specific to energy requirements for the sport, lacking nutrients and efficacy of dietary supplements for female athletes is warranted. Athletes should be encouraged to consume appropriate proportions of macronutrients, be taught how to make the right dietary choices on and off campus and select food that is nutrient dense.

\section{Acknowledgements}

We would like to thank our undergraduate student researchers for providing help with data collection and entry. In addition, we would like to thank Dr Takudzwa Madzima for providing writing assistance and proof reading the article. 


\section{REFERENCES}

Anderson, D. E. (2010). The Impact of Feedback on Dietary Intake and Body Composition of College Women Volleyball Players Over a Competitive Season. Journal of Strength and Conditioning Research, 24(8), 2220-2226. https://doi.org/10.1519/JSC.0b013e3181def6b9

Black, A. E., Goldberg, G. R., Jebb, S. A., Livingstone, M. B., Cole, T. J., \& Prentice, A. M. (1991). Critical evaluation of energy intake data using fundamental principles of energy physiology: 2. Evaluating the results of published surveys. European Journal of Clinical Nutrition, 45(12), 583-99.

Burke, L. M., Cox, G. R., Cummings, N. K., \& Desbrow, B. (2001). Guidelines for Daily Carbohydrate Intake. Sports Medicine, 31(4), 267-299. https://doi.org/10.2165/00007256-200131040-00003

Burke, L. M., Loucks, A. B., \& Broad, N. (2006). Energy and carbohydrate for training and recovery. Journal of Sports Sciences, 24(7), 675-685. https://doi.org/10.1080/02640410500482602

Campbell, B., Kreider, R. B., Ziegenfuss, T., La Bounty, P., Roberts, M., Burke, D., ... Antonio, J. (2007). International Society of Sports Nutrition position stand: protein and exercise. Journal of the International Society of Sports Nutrition, 4(1), 8. https://doi.org/10.1186/1550-2783-4-8

Clark, M., Reed, D. B., Crouse, S. F., \& Armstrong, R. B. (2003). Pre-and Post-season Dietary Intake, Body Composition, and Performance Indices of NCAA Division I Female Soccer Players. International Journal of Sport Nutrition \& Exercise Metabolism, 13, 303-319.

Driskell, J. A., Schake, M. C., \& Detter, H. A. (2008). Using Nutrition Labeling as a Potential Tool for Changing Eating Habits of University Dining Hall Patrons. Journal of the American Dietetic Association, 108(12), 2071-2076. https://doi.org/10.1016/j.jada.2008.09.009

Gallagher, D., Heymsfield, S. B., Heo, M., Jebb, S. A., Murgatroyd, P. R., \& Sakamoto, Y. (2000). Healthy percentage body fat ranges: an approach for developing guidelines based on body mass index. American Journal of Clinical Nutrition, 72(3), 694-701.

Guthrie, J. F., Lin, B.-H., \& Frazao, E. (2002). Role of Food Prepared Away from Home in the American Diet, 1977-78 versus 1994-96: Changes and Consequences. Journal of Nutrition Education and Behavior, 34(3), 140-150. https://doi.org/10.1016/S1499-4046(06)60083-3

Hassapidou, M. N., \& Manstrantoni, A. (2001). Dietary intakes of elite female athletes in Greece. Journal of Human Nutrition and Dietetics, 14, 391-396.

Hedrick Fink, H., \& Mikesky, A. E. (2015). Practical Applications in Sports Nutrition (4th ed.). Burlington, MA: Jones \& Barlet Learnings.

Hinton, P. S., Sanford, T. C., Davidson, M. M., Yakushko, O. F., \& Beck, N. C. (2004). Nutrient intakes and dietary behaviors of male and female collegiate athletes. International Journal of Sport Nutrition and Exercise Metabolism, 14(4), 389-405.

Institute of Medicine (IOM) Food and Nutrition Board. (2006). Dietary Reference Intakes: The Essential Guide to Nutrient Requirements. Washington, DC: National Academies Press.

Jeukendrup, A. E. (2003). Modulation of carbohydrate and fat utilization by diet, exercise and environment. Biochemical Society Transactions, 31(6).

Kohrt, W. M. (1998). Preliminary evidence that DEXA provides an accurate assessment of body composition. Journal of Applied Physiology, 84(1), 372-377.

Kolodinsky, J., Harvey-Berino, J. R., Berlin, L., Johnson, R. K., \& Reynolds, T. W. (2007). Knowledge of Current Dietary Guidelines and Food Choice by College Students: Better Eaters Have Higher Knowledge of Dietary Guidance. Journal of the American Dietetic Association, 107(8), 1409-1413. https://doi. org/10.1016/j.jada.2007.05.016

Kovacs, M. S. (2007). Tennis Physiology. Sports Medicine, 37(3), 189-198. https://doi.org/10.2165/00007256200737030-00001

Malousaris, G. G., Bergeles, N. K., Barzouka, K. G., Bayios, I. A., Nassis, G. P., \& Koskolou, M. D. (2008). Somatotype, size and body composition of competitive female volleyball players. Journal of Science and Medicine in Sport, 11, 337-344. https://doi.org/10.1016/j.jsams.2006.11.008

Martin, L., Lambeth, A., \& Scott, D. (2006). Nutritional Practices of National Female Soccer Players: Anlysis and Recommendations. Journal of Sports Science and Medicine, 5, 130-137.

Mullinix, M. C., Jonnalagadda, S. S., Rosenbloom, C. A., Thompson, W. R., \& Kicklighter, J. R. (2003). Dietary intake of female U.S. soccer players. Nutrition Research, 23, 585-593. https://doi.org/10.1016/S02715317(03)00003-4

Ousley-Pahnke, L., Black, D. R., \& Gretebeck, R. J. (2001). Dietary intake and energy expenditure of female collegiate swimmers during decreased training prior to competition. Journal of the American Dietetic Association, 101(3), 351-354.

Papadopoulou, S. K., Papadopoulou, S. D., \& Gallos, G. K. (2002). Nutrient Intake of Adolescent Volleyball Players / 71 Macro-and Micro-Nutrient Intake of Adolescent Greek Female Volleyball Players. International Journal of Sport Nutrition and Exercise Metabolism, 12, 71-78.

Pelletier, J. E., \& Laska, M. N. (2013). Campus Food and Beverage Purchases Are Associated With Indicators of Diet Quality in College Students Living Off Campus. American Journal of Health Promotion, 28(2), 80-87. https://doi.org/10.4278/ajhp.120705-QUAN-326

Petersen, H. L., Peterson, C. T., Reddy, M. B., Hanson, K. B., Swain, J. H., Sharp, R. L., \& Alekel, D. L. (2006). Body Composition, Dietary Intake, and Iron Status of Female Collegiate Swimmers and Divers. International Journal of Sport Nutrition \& Exercise Metabolism, 16(3), 281-295. 
Rodriguez, N. R., DiMarco, N. M., \& Langley, S. (2009). Position of the American Dietetic Association, Dietitians of Canada, and the American College of Sports Medicine: Nutrition and Athletic Performance. Journal of the American Dietetic Association, 109(3), 509-527. https://doi.org/10.1016/j.jada.2009.01.005

Sammarone Turocy, P., DePalma, B. F., Horswill, C. A., Laquale, K. M., Martin, T. J., Perry, A. C., ... Utter, A. C. (2011). National Athletic Trainers' Association Position Statement: Safe Weight Loss and Maintenance Practices in Sport and Exercise. Journal of Athletic Training, 46(3), 322-336.

Shriver, L. H., Betts, N. M., \& Wollenberg, G. (2013). Dietary Intakes and Eating Habits of College Athletes: Are Female College Athletes Following the Current Sports Nutrition Standards? Journal of American College Health, 61(1), 10-16.

Trumbo, P., Schlicker, S., Yates, A. A., \& Poos, M. (2002). Dietary Reference Intakes for Energy, Carbohydrate, Fiber, Fat, Fatty Acids, Cholesterol, Protein and Amino Acids. Journal of the American Dietetic Association, 102(11), 1621-1630. https://doi.org/http://dx.doi.org/10.1016/S0002-8223(02)90346-9

Tsunawake, N., Tahara, Y., Moji, K., Muraki, S., Minowa, K., \& Yukawa, K. (2003). Body Composition and Physical Fitness of Female Volleyball and Basketball Players of the Japan Inter-high School Championship Teams. Journal of Physiological Anthropology and Applied Human Science, 22(4), 195-201. https://doi. org/10.2114/jpa.22.195

US Department of Health and Human Services. (2015). 2015-2020 dietary guidelines for Americans. Washington (DC): USDA.

Valliant, M. W., Pittman Emplaincourt, H., Kieckhaefer Wenzel, R., \& Garner, B. H. (2012). Nutrition Education by a Registered Dietitian Improves Dietary Intake and Nutrition Knowledge of a NCAA Female Volleyball Team. Nutrients, 4(12), 506-516. https://doi.org/10.3390/nu4060506

Volpe, S. L. (2007). Micronutrient Requirements for Athletes. Clinics in Sports Medicine, 26, 119-130. https:// doi.org/10.1016/j.csm.2006.11.009

Wenzel Kieckhaefer, R., Valliant Wells, M., Chang, Y., Bomba K., A., \& Lambert G., L. (2012). Dietary assessment and education improves body composition and diet in NCAA female volleyball players. Topics in Clinical Nutrition, 27(1), 67-73. https://doi.org/10.1097/TIN.0b013e318246223b

Wilborn, C., Beckham, J., Campbell, B., Harvey, T., Galbreath, M., La Bounty, P., ... Kreider, R. (2005). Obesity: Prevalence, Theories, Medical Consequences, Management, and Research Directions. Journal of the International Society of Sports Nutrition, 2(22), 4-31. 